\title{
GRUPOS CERAMISTAS DA ILHA DE SOROBABEL, ITACURUBA-PE: CONTINUIDADE E MUDANÇA TECNOLÓGICA
}

Jade Paiva de Lima*

\author{
Ricardo Pinto de Medeiros ${ }^{* *}$ \\ Viviane Maria Cavalcante de \\ Castro $^{* *}$
}

\footnotetext{
* Bacharel em Arqueologia pela Universidade Federal de Pernambuco - UFPE

** Departamento de Arqueologia da Universidade Federal de Pernambuco - UFPE
}

RESUMO: $O$ presente trabalho pretende contribuir para 0 conhecimento da tecnologia cerâmica dos grupos ceramistas do Submédio São Francisco, através do estudo das técnicas utilizadas na manufatura do material cerâmico encontrado na Ilha de Sorobabel em Itacuruba - PE, proveniente dos sítios Ilha de Sorobabel e Missão Nossa Senhora do Ó que foram alvo de intervenção arqueológica na década de 80 pelo Projeto Itaparica de Salvamento Arqueológico e que se encontra depositado na Universidade Federal de Pernambuco. Foi realizada a análise dos fragmentos cerâmicos a partir de atributos técnicos e com o auxílio de análises de Difração de Raios $X$ e Microscópio, buscando verificar se houve uma continuidade ou mudança na tecnologia desses grupos após o contato com os europeus. Observou-se que os grupos que habitaram a llha de Sorobabel continuaram a utilizar alguns elementos das técnicas tradicionais de confecção da cerâmica em conjunto com novas técnicas assimiladas dos europeus e isso pode ser percebido na cultura material deixada por esses povos.

Palavras-chave: Ilha de Sorobabel, Tecnologia Cerâmica, Grupos Ceramistas.

ABSTRACT: This paper aims to contribute to the knowledge of pottery technology of Submedium São Francisco River potters groups, by studying the techniques used in the manufacture of ceramic material found on Sorobabel Island in Itacuruba, Pernambuco, from llha de Sorobabel and Missão Nossa Senhora do Ó sites, where happened an archaeological intervention in the 80 s by the Itaparica Archaeological Rescue Project and it is deposited at the Federal University of Pernambuco. That was perfomed the analysis of ceramic fragments from technical attributes and aided by X-ray diffraction analysis and microscope, seeking to verify if there was continuity or change in the technology of these groups after contact with europeans. It was observed the groups that inhabited the region continued to use some elements of the traditional techniques of making pottery, together with new techniques, assimilated from european and this can be seen in the material culture left by these people.

Keywords: Sorobabel Island, Pottery Technology, Pottery groups.engravings 


\section{Introdução}

As pesquisas arqueológicas realizadas no vale do São Francisco são de grande relevância para o conhecimento sobre os grupos pré-históricos que habitaram esta região, como também sobre as populações nativas que entraram em contato com os europeus. Martin (2013:128) ressalta que "os primitivos habitantes do vale do São Francisco descobriram a agricultura e aprenderam a fazer cerâmica, estabeleceram-se, principalmente, nas ilhas (...) as quais, com solo muito fértil, apresentam-se como verdadeiros oásis no meio do semiárido sanfranciscano". Para esta autora as ilhas foram intensamente ocupadas por populações de ceramistas e agricultores pré-coloniais e, posteriormente, por aldeamentos missionários.

Por meio do estudo da cerâmica é possível levantar hipóteses sobre diversos aspectos da vida das sociedades passadas, sejam eles, culturais, sociais, econômicos, religiosos, políticos (Luna, 2003). Como também se pode verificar se há, no material, características técnicas que atestem o contato com outros grupos e como esse contato influenciou na transformação de sua própria cultura.

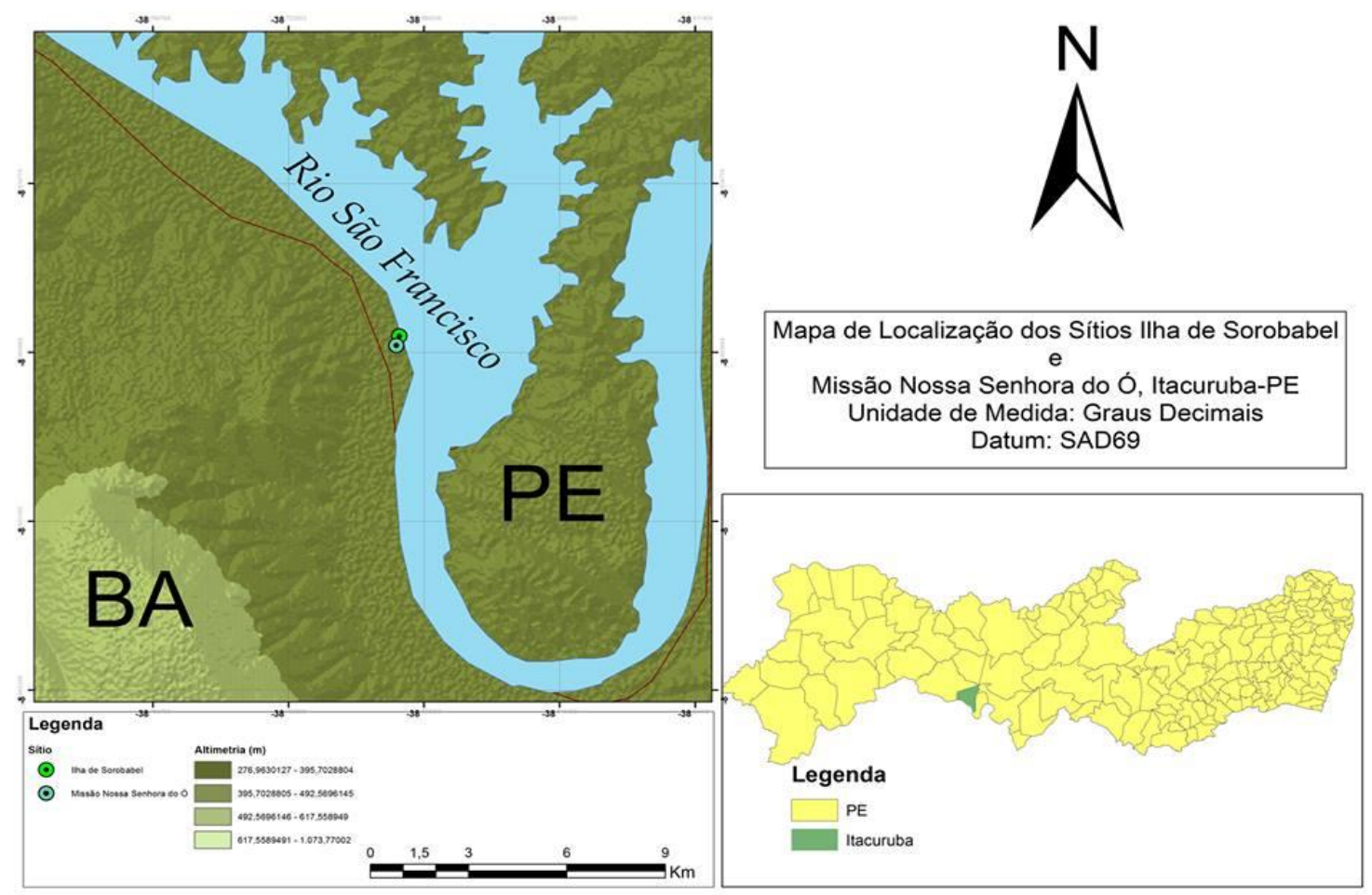

Figura 1: Localização dos Sítios Ilha de Sorobabel e Missão Nossa Senhora do Ó. Elaborado por: Bonald, 2015.

Os sítios arqueológicos estudados, Ilha de Sorobabel e Missão Nossa Senhora do Ó, estavam situados na Ilha de Sorobabel (Figura 1) que, atualmente, encontra-se inundada pelas águas da barragem de Itaparica. A Ilha, uma das maiores do São Francisco, localizava-se a $30 \mathrm{~km}$ a oeste do município de Itacuruba, Pernambuco, próxima a foz do rio Pajeú e tinha, aproximadamente, $3 \mathrm{~km}$ de comprimento por 0,3 km de largura (Silva, 2003). O material arqueológico desses sítios é proveniente do Projeto Itaparica de Salvamento Arqueológico (1981-1988). 
Este trabalho tem como objetivo de pesquisa verificar se houve continuidade ou mudança na tecnologia cerâmica, através do estudo das técnicas utilizadas na manufatura do material cerâmico encontrado nos sítios arqueológicos localizados na ilha de Sorobabel. Por meio deste estudo identificou-se o potencial de tal cultura material para prover conhecimentos sobre a tecnologia cerâmica dos grupos que viveram na região.

O projeto Itaparica de Salvamento foi realizado no período de 1981 a 1988, em decorrência da construção da barragem "Luiz Gonzaga", que inundou uma área de aproximadamente 834 $\mathrm{km}^{2}$, entre o leito menor do São Francisco e a cota máxima de inundação e as ilhas $(300 \mathrm{~m}$ acima do nível do mar). Tinha como objetivo identificar e resgatar os sítios arqueológicos da extensa área que seria inundada (Martin, 2013).

As pesquisas foram realizadas nos estados de Pernambuco e da Bahia em convênio com a Companhia Hidroelétrica do São Francisco - Chesf. A parte referente ao estado de Pernambuco ficou a cargo da Universidade Federal de Pernambuco, sob a coordenação de Gabriela Martin e do Núcleo de Estudos Arqueológicos - NEA daquela instituição de pesquisa, abrangendo os municípios de Petrolândia, Itacuruba, Floresta e Belém do São Francisco. Por sua vez no estado da Bahia os trabalhos ficaram sob a responsabilidade da Universidade Federal da Bahia e do Museu de Arqueologia e Etnologia, coordenado pelo antropólogo Pedro Agostinho e pelo arqueólogo Carlos Etchevarne, envolvendo os municípios de Abaré, Chorrochó, Rodelas e Glória. Os sítios arqueológicos foram identificados por meio de informações dos moradores e prospecções extensivas e intensivas nos terraços fluviais, abrigos sob-rocha e nas serras circundantes (Martin, 1998; Etchevarne, 2002).

\section{As Missões Religiosas no Vale do São Francisco}

O período colonial, a partir do século XVI, é marcado pelo início do extermínio dos grupos indígenas que habitavam a região, através de guerras e aprisionamentos dos mesmos, para serem transformados em escravos. Desse período existem vários relatos, como os de viajantes e missionários que trazem informações acerca dos povos indígenas da região, pelo menos dos que ficaram registrados nesses documentos que mostram a grande diversidade de etnias. Os índios que escaparam do extermínio ou aprisionamento fugiram para regiões distantes ou se refugiaram nas missões criadas por várias ordens religiosas no médio São Francisco (Luna e Nascimento, 2006).

Na segunda metade do século XVII os jesuítas iniciaram a criação das missões religiosas no vale do São Francisco. Posteriormente, vieram os capuchinhos franceses e os italianos. Os grupos de missionários que iniciaram a catequização dos povos indígenas do sertão do São Francisco se instalaram onde já existiam aldeias de índios que praticavam a agricultura e esses assentamentos estavam localizados principalmente nas ilhas do São Francisco (Martin, 1990).

Os padres da Companhia de Jesus em 1663 já possuíam cinco aldeias no Sertão e nas ilhas de Rodelas e em 1669 criaram mais três missões em Acará, Curumambá e Zorobabel, todas no vale do São Francisco, porém nesse mesmo ano os jesuítas foram expulsos pelos representantes da Casa da Torre. Após esses acontecimentos os jesuítas se recusaram a voltar 
a Zorobabel e as outras missões que foram, em seguida, oferecidas aos franciscanos, que de início recusaram e foram substituídos pelos carmelitas de Santa Teresa.

Posteriormente, os Franciscanos franceses passaram a assumir as três missões após o alvará de 1700 , confirmado pela lei de 1703 , se instalando na llha de Zorobabel e construíram a igreja e o recinto da missão, em tijolo e cantaria. A missão esteve sob a direção dos franciscanos franceses e italianos entre 1702 e 1761, ano em que foi extinta (Martin, 1990). Os índios Porcas e Brancararus habitavam a Missão de Nossa Senhora do Ó no século XVIII (Figura 2).

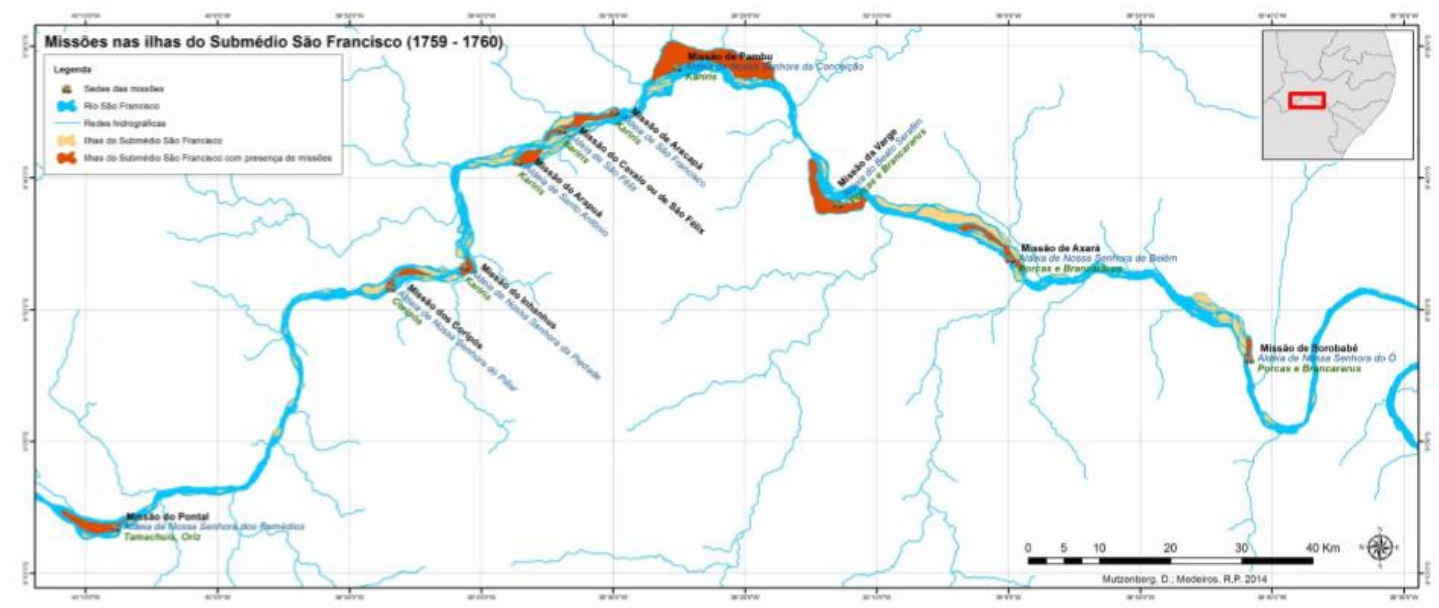

Figura 2: Localização das missões nas Ilhas do Submédio São Francisco (1759-1760). Fonte: Medeiros e Mutzenberg, 2014.

As pesquisas arqueológicas realizadas pelo Projeto Itaparica na região do submédio São Francisco se iniciaram na llha de Sorobabel, pois a mesma seria inundada pela barragem de Itaparica. Ainda existiam na ilha vestígios da antiga igreja da Missão de Nossa Senhora do Ó e durante as escavações realizadas foi localizada uma aldeia indígena no ponto mais alto.

\section{Os Sítios Arqueológicos Ilha de Sorobabel e Missão Nossa Senhora do Ó}

O sítio llha de Sorobabel está situado a $500 \mathrm{~m}$ das ruínas da Igreja de Nossa Senhora do Ó a $200 \mathrm{~m}$ do rio São Francisco. Foi caracterizado por Silva (2003) como sendo uma aldeia indígena pelos vestígios de cerâmica com engobo vermelho, encontrados no local, sem a intrusão de materiais europeus dispersos em um raio de 25 metros em torno de uma mancha circular (Silva, 2003).

De acordo com Martin:

A partir de informações dos moradores sobre a existência de "aribés", nome popular dado às vasilhas cerâmicas, realizaram-se prospecções no local e foram encontradas três urnas que continham restos ósseos humanos, além de um enterramento bastante calcinado envolto numa camada de cinzas, conchas bivalves, pingentes e contas de colar em osso e vidro, restos faunísticos, um peso de cerâmica e muitos fragmentos de cerâmica. Uma 
outra vasilha, que havia sido resgatada por um morador, foi doada à equipe e possui as mesmas características de uma das urnas encontradas nas escavações (Martin, 1998 p. 35).

Nesse sítio foi realizada uma escavação e no estrato superficial foram encontrados vários tipos de pingentes e contas de colar, junto a fragmentos de cerâmica; os vestígios encontrados em camadas inferiores não tinham características de contato com os Europeus. Em subsuperfície foram identificados fragmentos cerâmicos e ósseos, carvão e cinzas, material lítico, cachimbos e material malacológico (Silva, 2003). No sítio ainda foram encontradas quatro urnas funerárias que faziam parte de rituais de incineração.

O sítio Missão Nossa Senhora do Ó se localiza ao sul da llha de Sorobabel é constituído por um conjunto de edificações em ruínas e pode ser considerado em dois aspectos: "o da construção do templo e dependências, que presentifica a cultura transmigrada e o das inumações em covas abertas no pátio interno da Missão, que representavam a cultura das populações locais" (Silva, 2003: 259).

A igreja foi construída no começo do século XVIII, pelos capuchinhos franceses, seguindo os padrões das capelas barrocas dos séculos XVII-XVIII. A primeira igreja tinha as dimensões de 25,0 x 22,0 na direção NW - SE e foi construída em pedra, com paredes largas, rústicas e sem alinhamento. Houve a construção de uma nova igreja em tijolo e pedra com a utilização de argamassa de barro e cal com o piso feito de tijolos de forma retangular, e uma pequena capela lateral, existia também uma torre com cripta, atrás do altar-mor (Martin, 1990). Com a construção do templo maior e expansão das dependências da missão em alvenaria, a área da missão passou a ser de 40,0 x 25,0 na direção NE - SW.

Através das escavações realizadas durante o Projeto Itaparica foi possível o levantamento da planta da Igreja e do conjunto da missão (Figura 3). Martin (1990) ressalta que na área da missão, a cerâmica indígena foi encontrada misturada a vestígios de faiança europeia do século XVIII. Entre o pátio da missão e a igreja ainda foram encontrados ossos, material cerâmico, mós, moedores, vidro e alguns pregos. No entorno das ruínas foram encontrados pregos, travas de fechaduras, garrafas de vidro, grés, malacológico, louça portuguesa, peças de metal. Também foram encontradas vinte e uma fossas com enterramentos (Martin, 1990; Silva, 2003). 


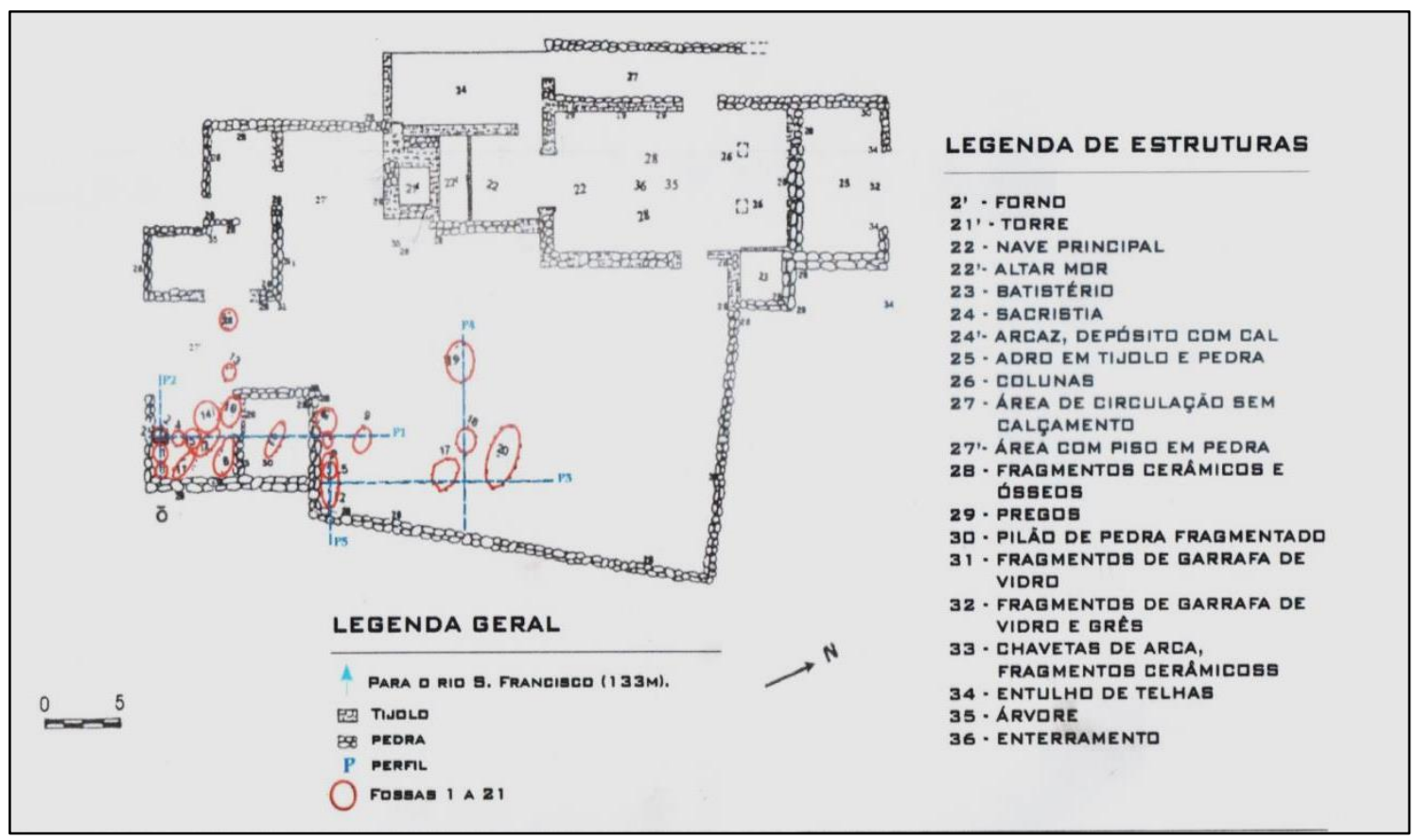

Figura 3: Planta baixa do Sítio Missão Nossa Senhora do Ó. Fonte: SILVA, 2003.

\section{Sistemas Técnicos no Estudo da Cerâmica Arqueológica}

Cada sociedade possui uma estruturação própria das etapas de manufatura dos objetos, que seguem uma ordenação e sequência lógica. As particularidades na produção da cultura material dos grupos permitem compreender os processos técnicos e as escolhas técnicas desenvolvidas pelos artesãos como também os processos sociais.

A partir do desenvolvimento do pensamento em conjunto com a técnica de confecção de objetos, o homem trabalha a matéria-prima e vai aprimorando suas habilidades a partir do saber fazer (Savoir Faire). Com o tempo e observação, as ideias vão surgindo e transformando a matéria em objeto fabricado. Segundo Chiara "os sistemas, mental e o técnico, são perfeitamente comunicáveis, são linguagens guiadas por um código que deve ser desvendado" (Chiara, 1998: 97).

As habilidades de manufatura e os diferentes materiais utilizados por uma determinada sociedade, assim como as relações culturais, podem ser perpetuados através da transmissão de conhecimentos técnicos. A técnica é definida por Mauss (2003) como: "um ato tradicional e eficaz (...). Não há técnica e não há transmissão se não houver tradição" (Mauss, 2003: 407). Portanto a técnica é aprendida e transmitida entre os membros de determinada sociedade. Para Lemmonier (1992: 3) "as técnicas são fenômenos sociais que podem variar de uma cultura para outra".

Segundo Schiffer e Skibo (1987) a tecnologia gira em torno de artefatos, do saber adquirido e comportamentos, para criar, transformar e utilizar objetos através do conhecimento assimilado por meio de seus ancestrais. De acordo com Lemmonier (1992) a tecnologia, como um todo, de determinado grupo é um sistema e suas técnicas podem ser assimiladas em três 
níveis. O primeiro seria o nível das técnicas em si, onde a técnica seria uma ação humana, constituída por elementos em conjunto, como os gestos, ferramentas, matéria e conhecimento; o segundo nível seria o estudo do conjunto de técnicas que formam o sistema tecnológico; o terceiro nível é o da relação entre o sistema tecnológico comparando-o com outros fenômenos culturais.

Seguindo o princípio de que o homem evolui no tempo e espaço, pressupõe-se que a sua mente também ultrapassa certos níveis de consciência, buscando, dessa forma, novos elementos que serão inseridos nas técnicas desenvolvidas pelo grupo, para o seu próprio benefício, ocasionando em mudanças tecnológicas na fabricação dos artefatos, sejam ideias, gestos ou conhecimentos que são inseridos. Estes devem ser compatíveis e podem acrescentar algo à técnica já desenvolvida, caso contrário, esta inovação não será absolvida pelo grupo. Com isso a tecnologia de um grupo só poderá se desenvolver e se modificar seguindo uma trajetória lógica, de acordo com os parâmetros estabelecidos pela cultura da qual faz parte, pois há uma relação íntima entre a tecnologia e a sociedade que a produz (Zuse, 2009; Viana, 2005). Ainda de acordo com Zuse (2009):

A mudança na técnica pode ocorrer em função da modificação em alguma(s) das operações da cadeia operatória, de uma alteração do saber técnico tradicional, ou dos gestos técnicos utilizados no processo, que pode decorrer de um novo aprendizado que transforma as normas técnicas vigentes. (Zuse, 2009: 46).

Nobre (2013) comenta que quando novos elementos vão sendo incorporados à técnica desenvolvida por determinado grupo, que podem ser adquiridos através da observação da técnica utilizada por outros grupos, ocorre uma heterogeneidade na tecnologia desse povo; porém há maior semelhança entre esses grupos. De acordo com Viana (2005: 65) a "mudança tecnológica pode ser entendida como transformação de um objeto, diferente de inovação ou empréstimo, esses conceitos estão de alguma forma envolvidos, pois todos levam, em tempos e maneiras distintas, a uma mudança tecnológica no sistema de produção".

É possível compreender que várias mudanças podem ocorrer na tecnologia de produção dos artefatos cerâmicos de um determinado grupo ao longo do tempo, como também pode haver uma escolha, dos artesões, dentro desse grupo, em manter os elementos originais caracterizadores de sua cultura, perpetuando assim uma tradição que passa de geração para geração em forma de cultura material. Portanto, o que leva o indivíduo a confeccionar o objeto, além da necessidade de utilização do mesmo, é o intuito de manter sua identidade através da tradição.

As etapas de produção de um objeto, fabricado, usado ou trocado, estão relacionadas com as práticas e sistemas de pensamento. Os sistemas técnicos são práticas integradas a um saber fazer mental que vai além da ação aplicada sobre a matéria sendo o principal elemento envolvido na invenção ou transformação destes objetos (Lemmonier, 1992). 
Um sistema técnico é definido como um conjunto de estruturas ou o conjunto de técnicas desenvolvidas por determinado grupo, que podem ser evidenciadas através da criação de um perfil técnico. Essas técnicas serão verificadas a partir das características e elementos culturais contidos no perfil (Oliveira, 2000).

O perfil técnico é um instrumento de análise definido por um conjunto de características contidas nos objetos que permitam verificar quais os elementos que identificam o processo técnico (Pessis, 1993). Para uma melhor caracterização do material cerâmico, neste trabalho foi elaborado o perfil técnico cerâmico de cada sítio estudado.

\section{Metodologia}

O material cerâmico foi analisado de acordo com a proposta tecnológica, na qual foram verificados elementos específicos, desde a matéria-prima até o produto final (o objeto), que são utilizados para definir o perfil técnico cerâmico de um sítio. Em seguida realizou-se a análise comparativa entre os perfis técnicos cerâmicos dos sítios llha de Sorobabel e Missão Nossa Senhora do Ó. A partir da escolha de atributos para a análise dos fragmentos cerâmicos, baseados nos termos utilizados por Chmyz (1976), La Salvia e Brochado (1989) e Rye (1981), foi

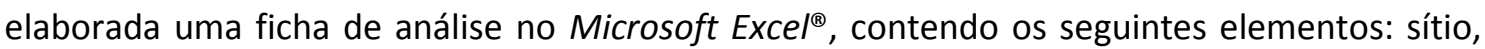
nível, setor, pasta, unidade, grupo, tipo, manufatura, queima, tratamento externo, tratamento interno, cor, decoração, tipo e espessura do lábio, da borda, do bojo e da base.

O atributo pasta é o primeiro a ser identificado no material cerâmico em estudo. Segundo Chmyz (1976, p. 137) pasta (paste) é uma "mistura de barro e antiplástico ou tempero, usada na confecção cerâmica". A definição das pastas foi realizada levando em consideração a textura (argila e antiplástico), a quantidade de antiplásticos e o tamanho e distribuição dos minerais. Com isso foram definidos 5 tipos de pasta de acordo com os critérios de La Salvia e Brochado (1989) e Caldarelli (2003):

\begin{tabular}{|c|l|}
\hline Pasta 01 & $\begin{array}{l}\text { Seca - Possui uma grande quantidade de antiplástico - } 50 \% \text { a } 75 \% \\
\text { (areia grossa na maioria dos fragmentos, grãos medindo entre } 2 \mathrm{~mm} \text { e } 5 \mathrm{~mm} \text { ou } \\
\text { maiores). }\end{array}$ \\
\hline Pasta 02 & $\begin{array}{l}\text { Medianamente plástica - Possui praticamente a mesma quantidade de antiplástico } \\
\text { e argila, contém areia fina e grossa com grãos de } 2 \mathrm{~mm} \text { e } 3 \mathrm{~mm} \text {, podendo ter grãos } \\
\text { maiores dispersos. }\end{array}$ \\
\hline Pasta 03 & $\begin{array}{l}\text { Plástica - Possui pouco antiplástico (areia fina na maioria dos fragmentos, com } \\
\text { grãos medindo cerca de } 1 \mathrm{~mm} \text { ), contém mais argila - 50\% a 75\%. }\end{array}$ \\
\hline Pasta 04 & $\begin{array}{l}\text { Plástica (Areia + Bolo de Argila) - Contém a mesma quantidade de antiplástico da } \\
\text { pasta 3 + bolos de argila (com grãos medindo de 2mm à 4mm). }\end{array}$ \\
\hline Pasta 05 & Pasta plástica com grãos de areia muito finos medindo cerca de $1 \mathrm{~mm}$ ou menores. \\
\hline
\end{tabular}

Para a identificação de minerais e outras estruturas cristalinas, orgânicas ou inorgânicas, presentes nos vestígios cerâmicos foram realizados Difrações de Raios X. Porém, a composição 
de alguns minerais pode ser alterada após a queima em altas temperaturas, como é o caso da Caulinita que não aparece no difratograma após um aquecimento a $550{ }^{\circ} \mathrm{C}$, com isso pode-se avaliar a temperatura da queima da cerâmica que pode ser determinada pela presença de certos minerais. Os compostos que são estudados com frequência são quartzo, feldspato, mica, ilita, caulinita, entre outros minerais.

Após a identificação e divisão dos fragmentos pelo tipo de pasta foram estabelecidas as Unidades através de conjuntos de fragmentos que continham características em comum: o mesmo tipo de antiplástico e o mesmo tratamento de superfície externa - TSE (Nascimento e Luna, 1994). Os tratamentos de superfície são todas as ações de acabamento, tanto de cunho prático como decorativo, que são aplicadas às superfícies tanto externa como interna, das peças cerâmicas.

Dentro de cada unidade foram separados os fragmentos que pudessem fornecer dados seguros quanto a morfologia e não apenas a identificação da pasta; estes foram considerados como diferidos, exceto os fragmentos de lábios e bordas. Os fragmentos que não possibilitaram uma verificação do tratamento de superfície externa - TSE e morfologia, ou estavam erodidos, foram classificados como residuais. A partir da divisão em Unidades criaram-se Grupos com a separação dos fragmentos pelos tipos de tratamento de superfície interna - TSI. Portanto, os fragmentos que possuíam o mesmo tipo de tratamento de superfície constituíram um Grupo cerâmico dentro de cada Unidade. Desta maneira, foram identificados na cerâmica arqueológica dos sítios Ilha de Sorobabel e Missão Nossa Senhora do Ó 17 unidades e 40 grupos.

Após as etapas de divisão das Unidades e dos Grupos, os fragmentos cerâmicos foram analisados, considerando principalmente os elementos que compõem o perfil técnico cerâmico que é caracterizado por elementos técnicos, morfológicos, funcionais (como fuligem e marcas de uso) e estilísticos, organizados hierarquicamente (Oliveira, 2000).

A análise da manufatura foi baseada na observação das marcas de superfície (externa e interna), que são resultado dos processos de confecção de cada peça, podendo ser impressões deixadas por algum instrumento utilizado ou mesmo pela mão do ceramista. Outra marca seria o tipo de fratura, como no caso do roletado, onde é possível visualizar as marcas de negativo e/ou positivo dos roletes, presentes na fratura dos fragmentos (Rye, 1981). As técnicas de manufatura foram definidas segundo a "Terminologia Arqueológica Brasileira Para a Cerâmica" (Chmyz, 1976).

A queima foi classificada apenas segundo as marcas que podem ser verificadas no núcleo e extremidades da pasta, como sendo completa ou incompleta. A queima completa apresenta uma cor uniforme no seu núcleo e extremidades e a incompleta apresenta uma variação das cores do núcleo e extremidades (Figuras 4 e 5). 


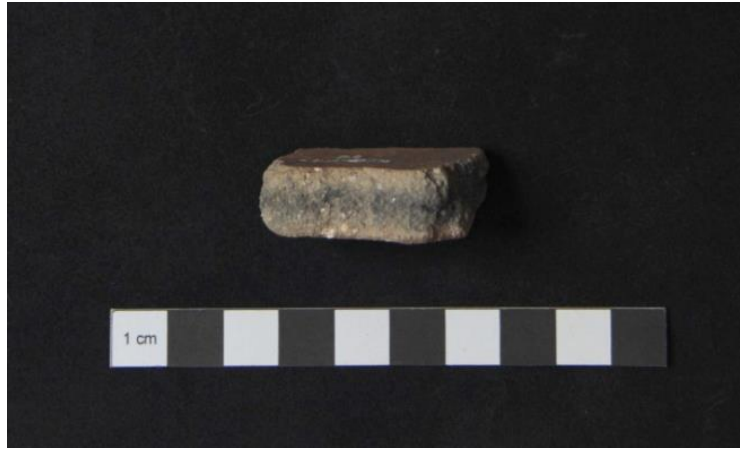

Figura 4: Fragmento de cerâmica com queima completa. Fonte: Lima, 2015

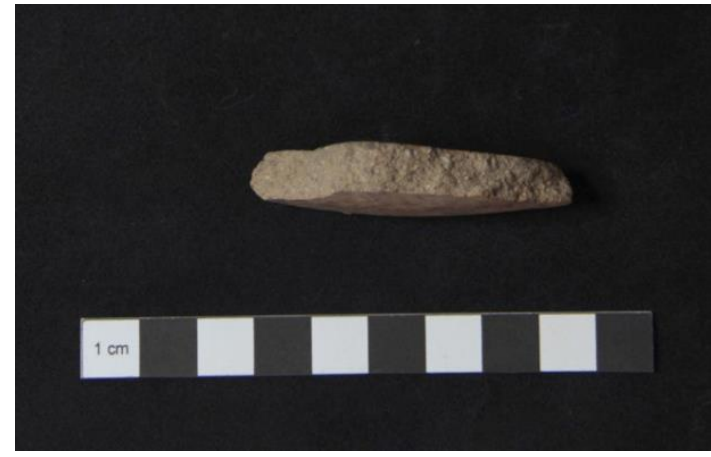

Figura 5: Fragmento de cerâmica com queima incompleta. Fonte: Lima, 2015

Para a reconstituição gráfica da forma dos vasilhames foram selecionados alguns fragmentos de borda/bojo que apresentassem no mínimo $1 / 4$ da peça cerâmica. 0 diâmetro da boca dos vasilhames foi obtido através da utilização do método dos círculos concêntricos. Esta forma de reconstituição é apenas hipotética, pois não havia todos os elementos necessários para a reconstituição das formas das vasilhas.

Os desenhos foram digitalizados e utilizou-se o software autocad ${ }^{\circledR}$ para a reconstituição em 3D da forma dos vasilhames, e, com isso foram verificados as dimensões e volume dos objetos para posterior classificação quanto a sua forma. O princípio de classificação dos objetos foi baseado nas formas dos sólidos geométricos de acordo com Tejero e Litivak (1968), Shepard (1963), Ericson e Stickes (1973) e Scatamacchia (2004). Para a classificação das formas é considerado principalmente o corpo ou parte, dos objetos que possam ser identificados em uma das formas geométricas: esférica, elipsoide horizontal, elipsoide vertical, ovoide, ovoide invertido. Além da forma geométrica também foram utilizados outros parâmetros como o contorno do corpo, a simetria, o diâmetro e abertura da boca e a altura total da vasilha.

Os vasilhames foram agrupados segundo os tamanhos definidos por Castro (1999) e Oliveira (2000):

\begin{tabular}{|l|l|}
\hline$P P$ & volume $<0,150 I$ \\
\hline$P$ & volume de $0,150<1 I$ \\
\hline$M$ & volume de $1 I<4 I$ \\
\hline$G$ & volume de $4 I<16 I$ \\
\hline$E G$ & volume de $16 I<50 I$ \\
\hline
\end{tabular}

\section{A Tecnologia de Produção da Cerâmica na Ilha de Sorobabel}

\section{Perfil Técnico Cerâmico do Sítio Ilha de Sorobabel}

O conjunto cerâmico do sítio llha de Sorobabel é formado por 1092 fragmentos dos quais 881 constituem as unidades analisadas e 149 foram classificados como diferidos por não possuírem elementos identificadores de sua morfologia, só sendo observado nos mesmos apenas o tipo de pasta. A classe residual é constituída por 62 fragmentos que não foram analisados por possuírem uma ou ambas as superfícies erodidas. 
No sítio llha de Sorobabel foi observada a presença de quatro tipos distintos de pastas, utilizados para manufatura dos vasilhames (Gráfico 1). A pasta 4 aparece em apenas 5 fragmentos isso pode indicar que seria utilizada para objetos específicos ou seria uma técnica mais elaborada que apenas poucos artesãos tinham conhecimento sobre a mesma. A pasta 3 é a mais frequente tanto nos fragmentos quanto nos poucos objetos que foram reconstituídos, houve uma preocupação na seleção dos grãos dessa pasta que são finos na maioria dos fragmentos $(0,2 \mathrm{~cm}$ à $0,3 \mathrm{~cm})$.

Gráfico 1: Tipos de pasta identificados nos fragmentos analisados do sítio Ilha de Sorobabel.

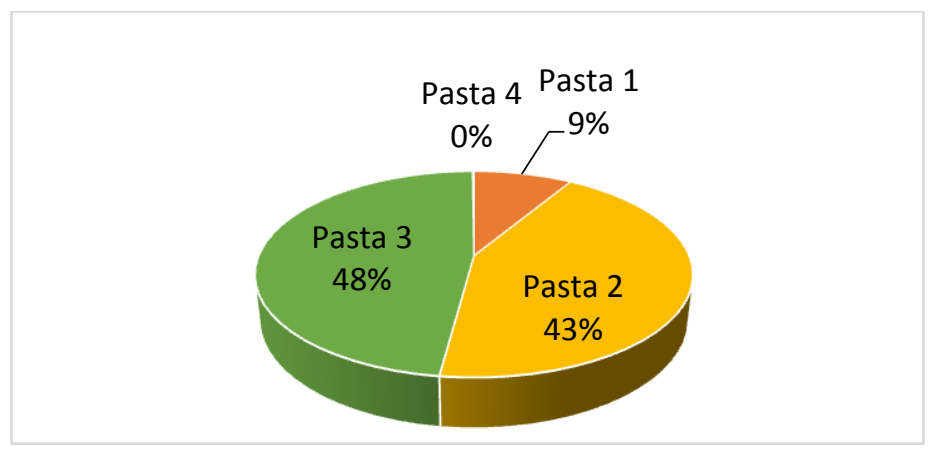

Gráfico 2: Representação gráfica dos tipos de tratamentos de superfície externa encontrados no sítio Ilha de Sorobabel.

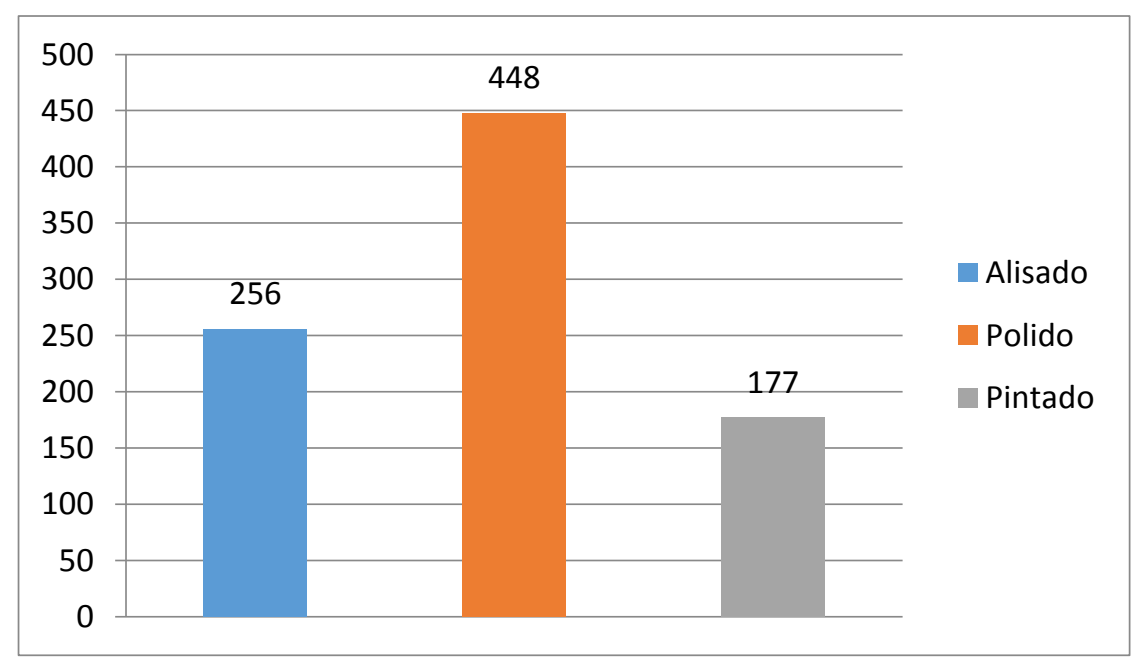

Foram identificados os seguintes tipos de tratamento de superfície: Alisado, Polido, Pintado, Escovado, Inciso, Ponteado e Ungulado (Gráficos 2 e 3). 0 tratamento de superfície polido foi predominante, sendo os fragmentos com esse tipo de técnica executada de forma eficaz. 0 polimento foi bem realizado, podendo esse tipo de tratamento fazer parte de um grupo de vasilhas utilizadas para uso específico; como também predomina a queima completa na maioria dos fragmentos, indicando um processo mais controlado. O tratamento de superfície alisado foi o segundo predominante; os fragmentos que contém este tipo de tratamento estavam, em sua maioria, bem alisados. 
Gráfico 3: Representação gráfica da frequência dos tipos de Tratamento de Superfície Interna dos fragmentos analisados do sítio llha de Sorobabel.

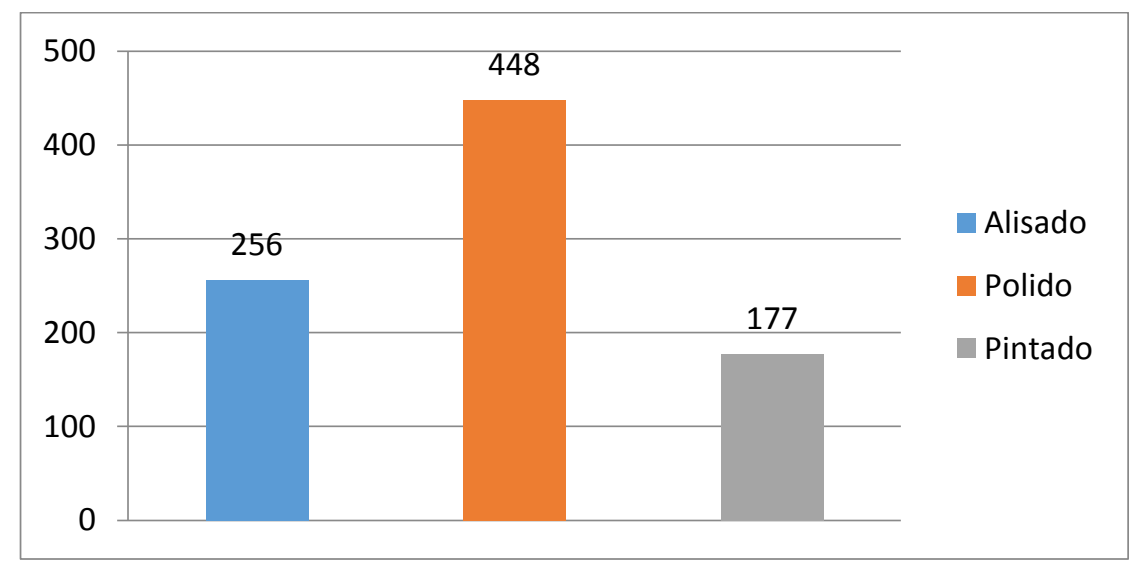

Poucos fragmentos encontrados possuíam tratamento pintado com motivos decorativos de linhas ou pontos; estes poderiam fazer parte de um grupo de cerâmicas de uso mais restrito, e, talvez, podem ter sido utilizadas para rituais. Foram encontrados fragmentos pintados nas cores, vermelho (Figura 6), vermelho com branco, preto e amarelo, em diversos tons (Vermelho 7.5R 4/6; 7.5R 5/6; 10R 5/6; 2.5YR 5/6; Vermelho Fraco 7.5R 4/2; 7.5R 4/4; 7.5R 5/4; 10R 5/4; Vermelho Claro 10R 6/8; Cinza Escuro 2.5Y 3/1; Marron pálido 10YR 8/4).

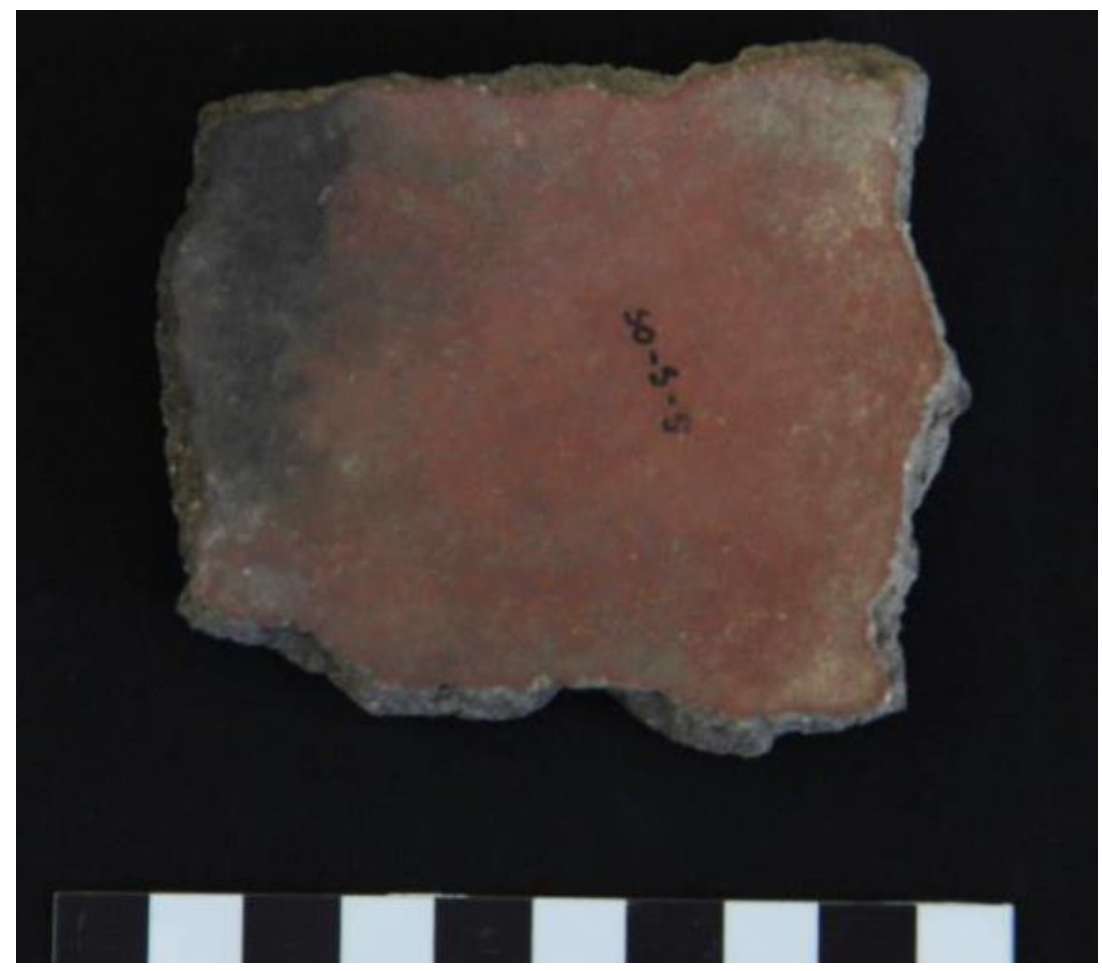

Figura 6: Fragmento de Bojo com decoração pintada em vermelho na parte interna. Fonte: Lima, 2015

Foi constatada uma homogeneidade na morfologia das bordas, com bordas diretas a totalidade das identificadas, isso pode ser reflexo das escolhas dos artesãos desse grupo de 
manter esse elemento passando de geração em geração. Os tipos de lábios identificados apresentam variação com lábios planos, arredondados e apontados.

Quanto a decoração plástica, os fragmentos tinham paredes mais grossas e a pasta possuía grãos maiores $(0,4 \mathrm{~cm}$ à $0,6 \mathrm{~cm})$ dispersos e as com decoração pintada possuíam uma pasta de grãos mais finos, demonstrando uma melhor seleção do tipo de aditivo das pastas. A decoração plástica mais encontrada foi o escovado, seguida do inciso, ponteado e o ungulado apenas realizado em um fragmento.

Algumas formas de vasilhas foram reconstituídas de forma hipotética: das quatro vasilhas reconstituídas três são elipsoide horizontal (Figura 7) com contorno simples e boca ampliada e uma é ovoide com contorno simples e boca ampliada; variam entre os tamanhos pequeno e médio.
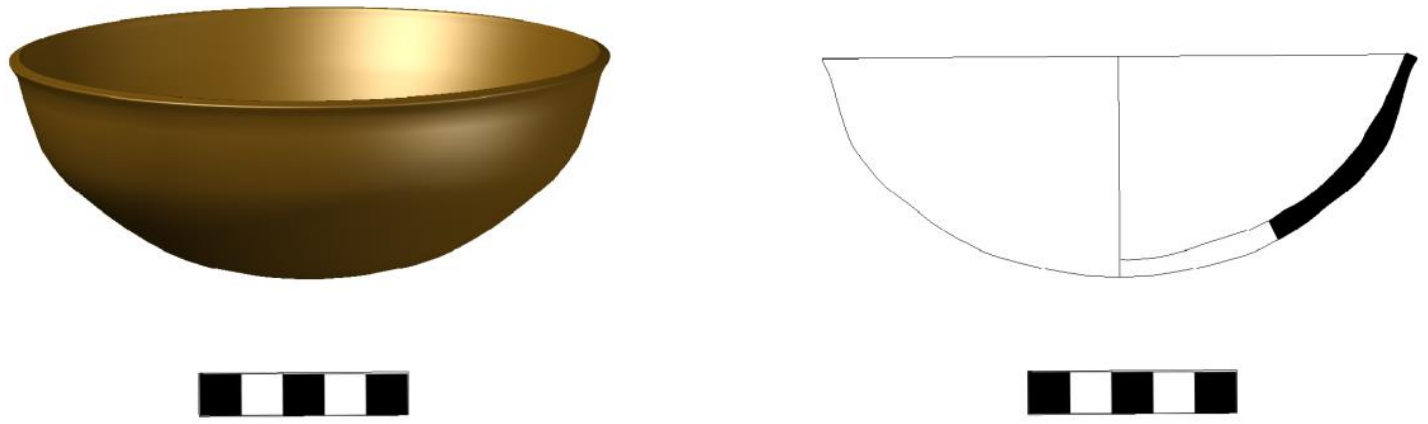

Figura 71: Reconstituição da forma elipsoide horizontal do sítio Ilha de Sorobabel. Fonte: Lima, 2015

A presença de apêndices do tipo alça pode indicar a função das vasilhas, que havia a necessidade de suspender as mesmas, talvez para um melhor transporte. Foi encontrado apenas um apêndice do tipo alça e o mesmo estava em um bojo com tratamento externo e interno polido e confeccionado com a pasta 3 (Figura 8).

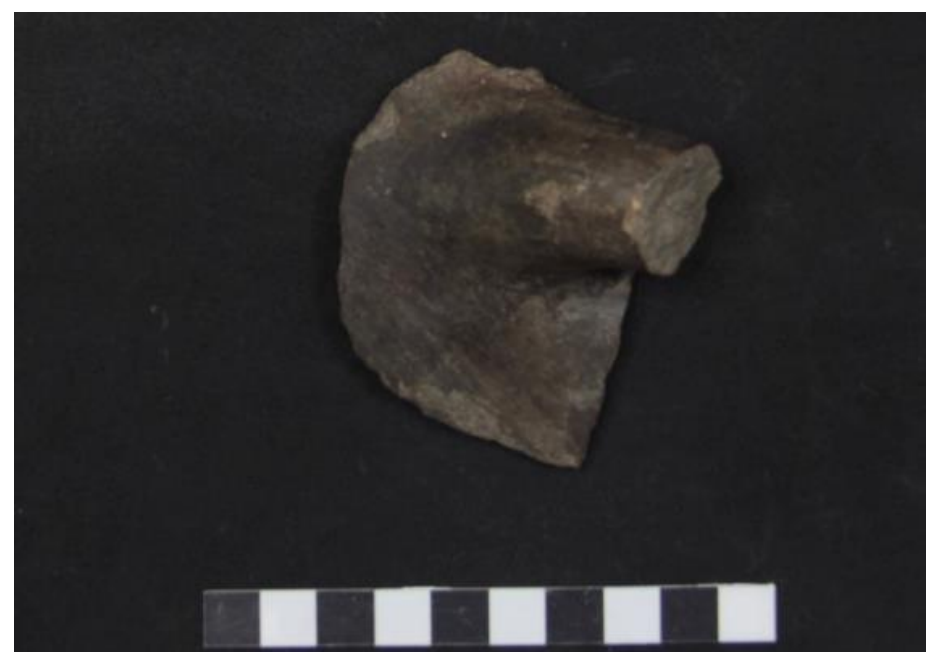

Figura 8: Fragmento de apêndice do tipo alça encontrado no sítio llha de Sorobabel. Fonte: Lima, 2015 
Outro indicador de função é o tamanho das vasilhas. Nesse sítio as vasilhas foram classificadas como de tamanho médio, e, provavelmente podem ter sido utilizadas para uso doméstico e as urnas funerárias que tem sua função já estabelecida para enterramentos, mas podem ter sido utilizadas para armazenar alimentos antes de serem usadas como urnas, não voltando a sua função inicial.

\section{Perfil Técnico Cerâmico do Sítio Missão Nossa Senhora do Ó}

O sítio Missão Nossa Senhora do Ó, apresenta dois perfis cerâmicos. No primeiro perfil integram os fragmentos que possuem características, mesmo que com alguns elementos modificados na manufatura, da cerâmica produzida pelos nativos, na qual foi possível fazer comparações com a cerâmica do sítio llha de Sorobabel. O outro perfil é caracterizado por uma cerâmica classificada em leve e vitrificada de manufatura torneada; essa cerâmica possui características distintas dos outros tipos de cerâmica encontrados nos sítios estudados.

\section{Perfil cerâmico 1}

O conjunto cerâmico que forma o perfil cerâmico 1 é composto por 1824 fragmentos dos quais 1616 formam as Unidades analisadas e 208 a classe diferida. A classe residual é composta por 131 fragmentos que não foram analisados.

Para esse perfil do sítio Missão Nossa Senhora do Ó foram definidas quatro pastas. Houve predominância da pasta 2 , seguido da pasta 3 , depois a pasta 1 e por fim a pasta 4 . Verificouse uma predominância da areia grossa, mas com grãos bem distribuídos (Gráfico 4). Os apêndices e aplique encontrados foram confeccionados com pasta 3 e 4 de grãos mais finos.

Gráfico 4: Tipos de pasta identificadas nos fragmentos analisados do sítio Missão Nossa Senhora do Ó.

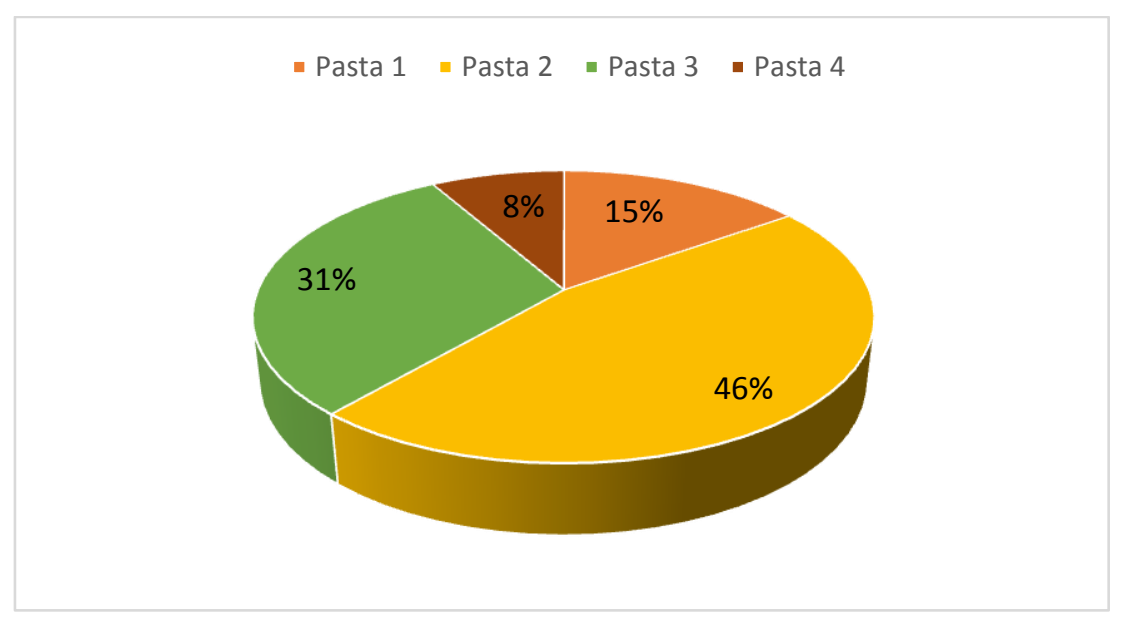

Os fragmentos desse sítio permitiram uma melhor identificação morfológica. Verificou-se a predominância de fragmentos de bojo $(74,2 \%)$ simples, e bases planas. Identificaram-se dois tipos de borda com predominância de bordas diretas (79\%) e extrovertidas (6\%). Os tipos de lábios, em maioria são planos (53\%), seguidos dos arredondados (33\%). 
No sítio foram identificados os seguintes tipos de tratamento de superfície: Alisado, Polido, Pintado, Escovado, inciso e digitado (Gráficos 5 e 6). As duas últimas técnicas são consideradas apenas com função decorativa. $O$ tratamento de superfície polido é predominante em ambas às superfícies da peça (Figura 9). O tratamento de superfície pintado foi encontrado em 90 fragmentos nas cores vermelho, vermelho com preto, vermelho com branco, branco (Vermelho 7.5R 4/6; 7.5R 5/6; 10R 6/6; Vermelho Fraco 7.5R 4/2; 7.5R 5/4; 10R 5/4; Vermelho Claro 10R 6/8; 2.5 YR 7/6; 2.5 YR 6/6; Marron pálido 10YR 8/4) e alaranjado em vários tons; contudo, não foi identificado nenhum motivo decorativo nos fragmentos.

Gráfico 5: Representação gráfica dos tratamentos de superfície externa encontrados no sítio Missão Nossa Senhora do Ó.

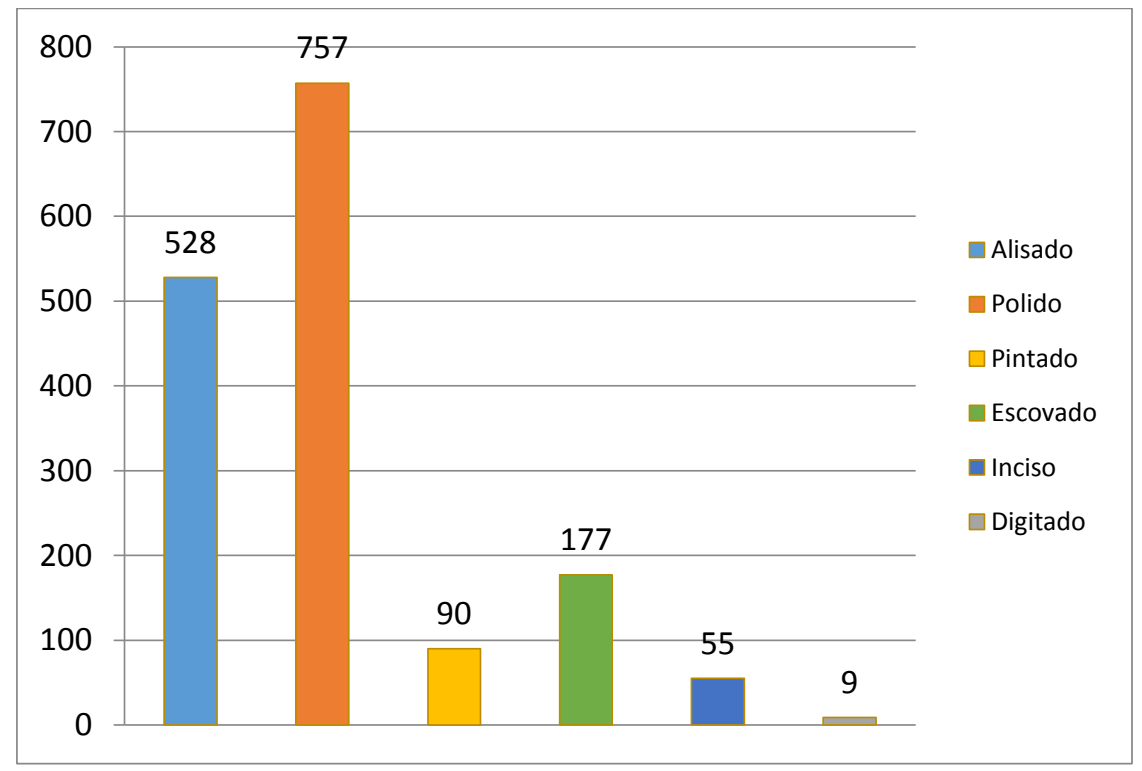

Gráfico 6: Representação gráfica dos tratamentos de superfície interna encontrados no sítio Missão Nossa Senhora do Ó.

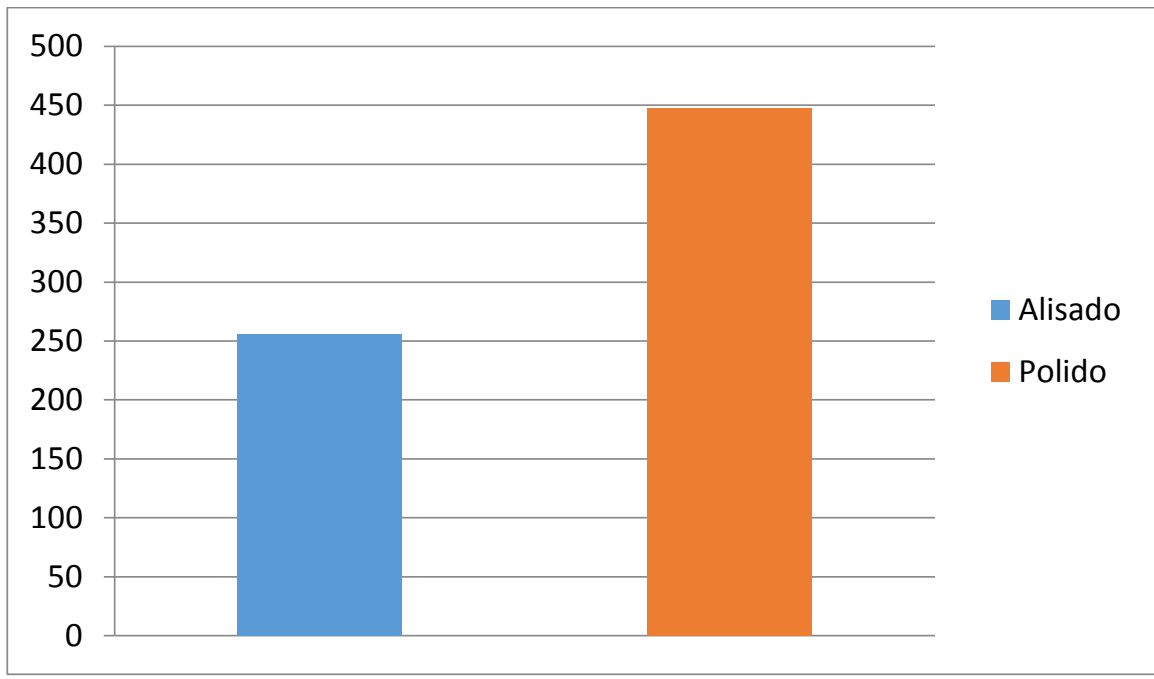




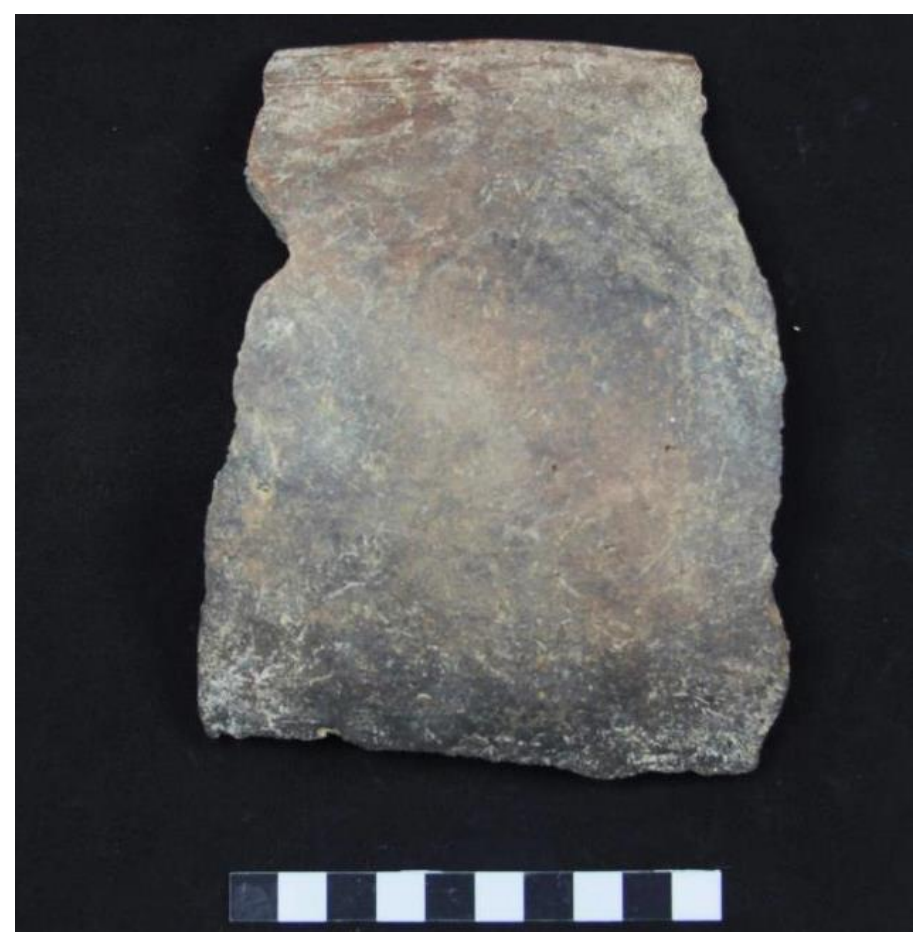

Figura 9: Fragmento de borda/bojo com tratamento de superfície externa polido do sítio Missão Nossa Senhora do Ó. Fonte: Lima, 2015

O escovado foi o tratamento plástico mais empregado nesse sítio, e pode ter sido utilizado mais com uma função prática do que decorativa, devido a maior segurança para manuseio dessas peças, pois se identifica que as mesmas eram vasilhas grandes e possuíam espessura de parede que variam de $0,7 \mathrm{~cm}$ a $02 \mathrm{~cm}$; percebeu-se também a associação da pasta 01 e 02 ao tratamento de superfície externo escovado (Figura 10).

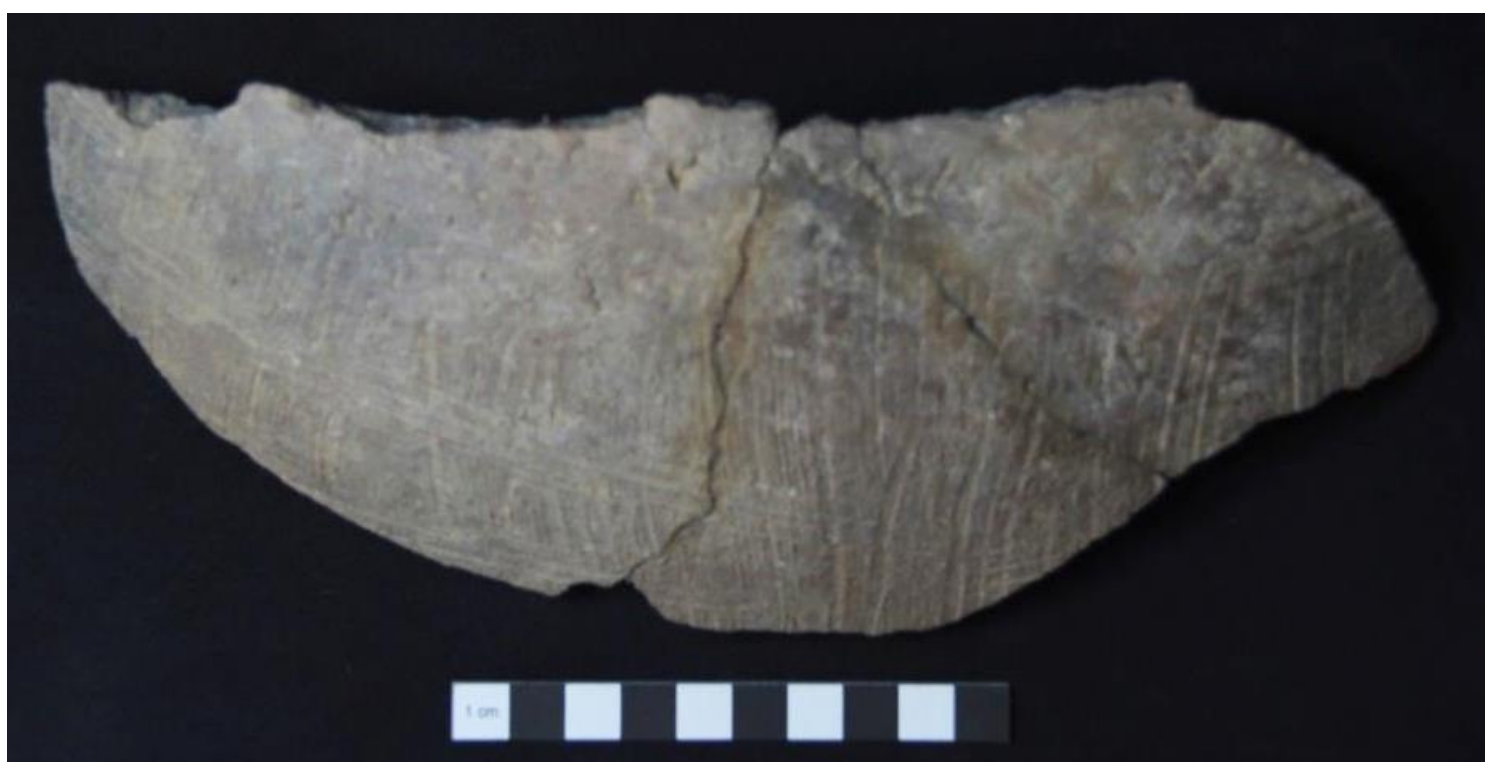

Figura 10: Fragmentos de bojo colados com tratamento de superfície externa escovado, do sítio Missão Nossa Senhora do Ó. Fonte: Lima, 2015. 
O digitado foi verificado em algumas peças em associação com o tratamento escovado, podendo ser algo intencional do artesão e as vasilhas podem ter sido utilizadas para uso específico (Figura 11).

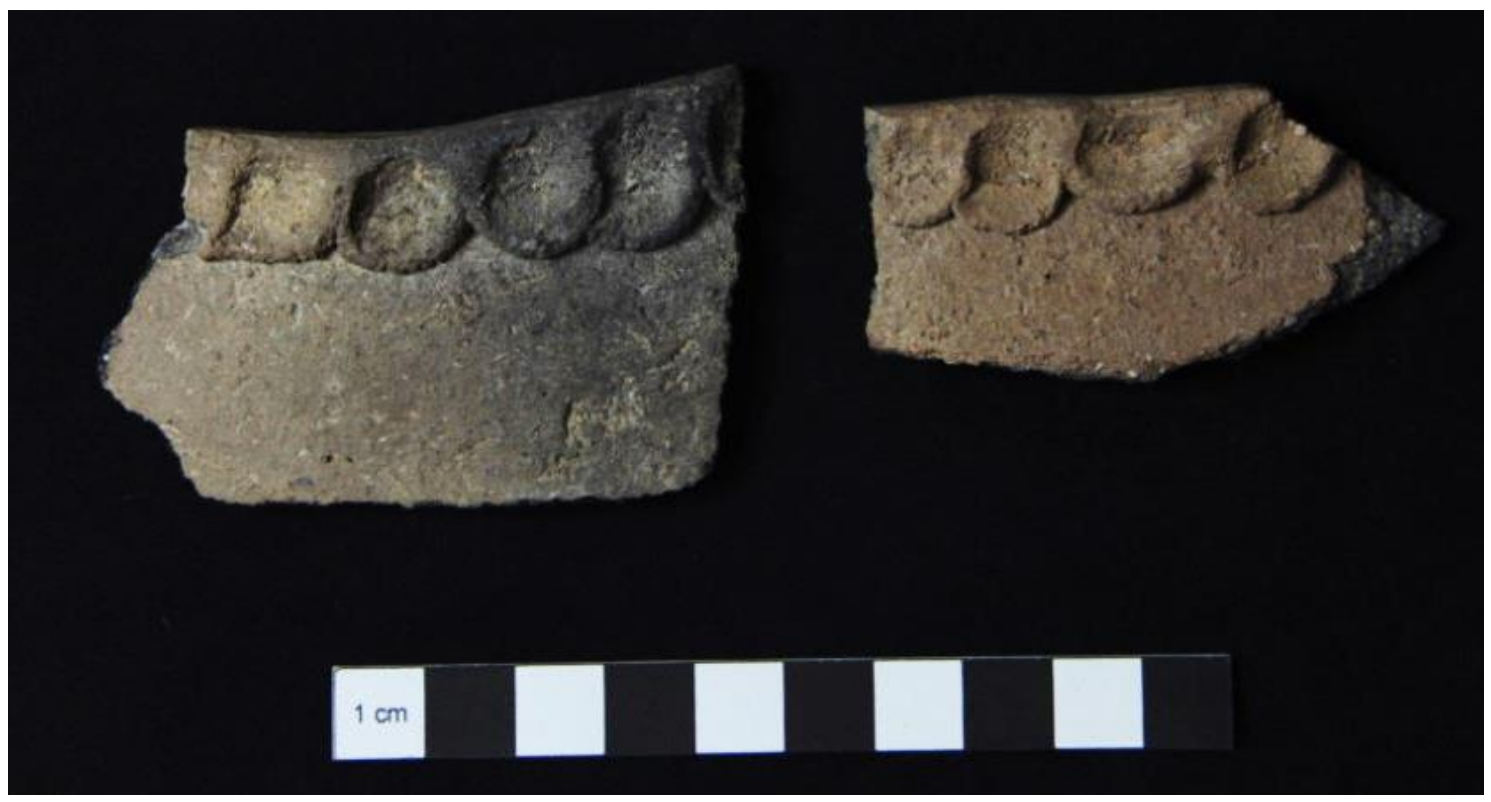

Figura 11: Bordas com técnica de tratamento plástico digitado do sítio Missão Nossa Senhora do Ó. Fonte: Lima, 2015.

As formas encontradas no sítio possuem maior diversidade e são maiores. Foi realizada a reconstituição hipotética de seis tipos de formas de vasilhas nesse sítio, com tamanhos M e G: elipsoide horizontal de boca ampliada e boca constrita, ovoide e esférica (Figuras 12 e 13).
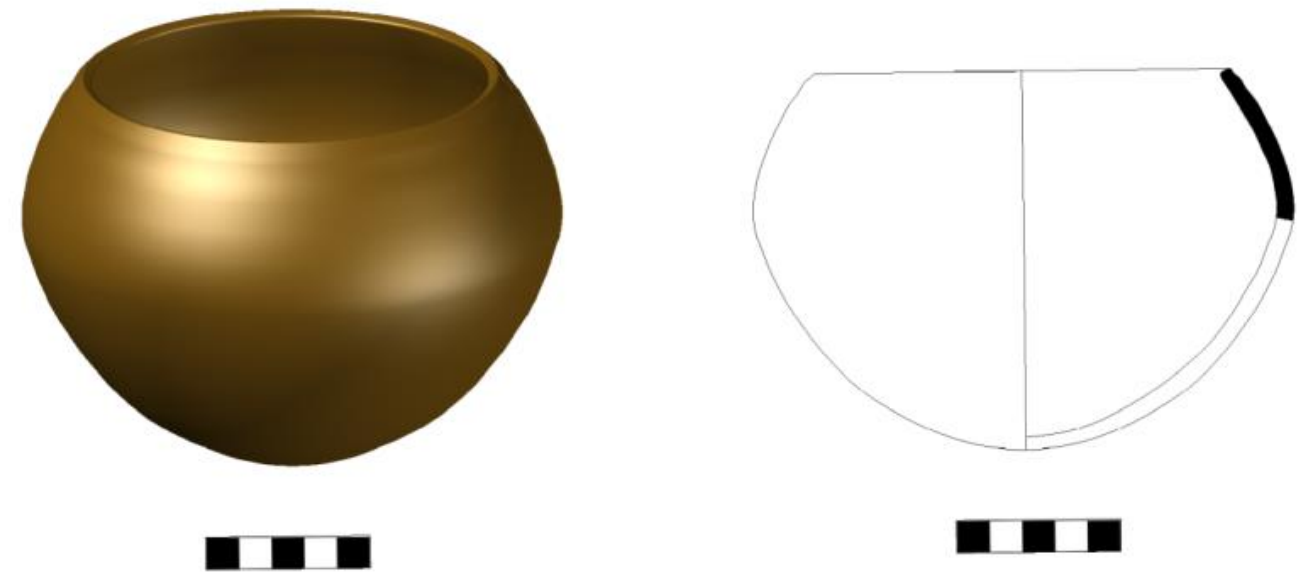

Figura 12: Reconstituição da forma ovoide do sítio Missão Nossa Senhora do Ó. 


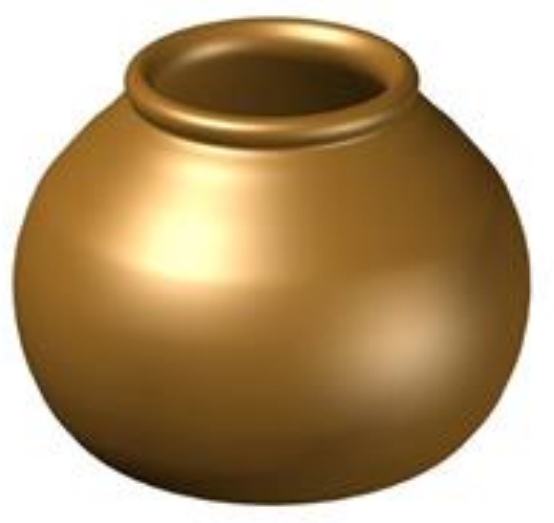

a

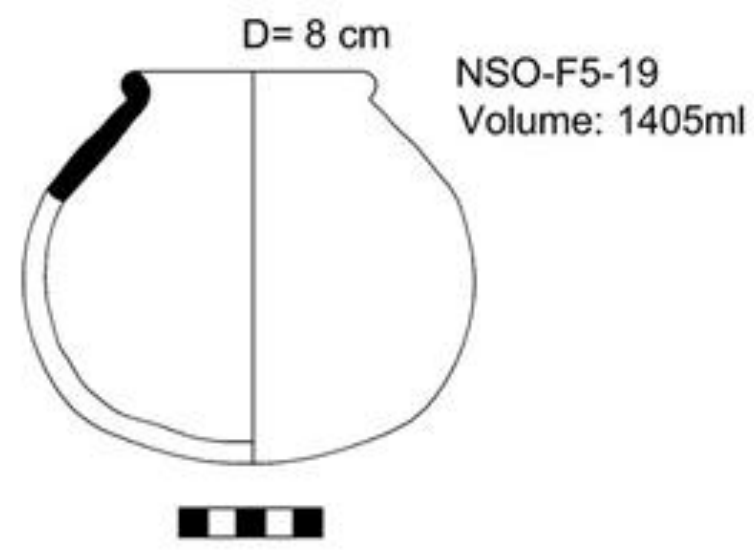

Figura 13: Reconstituição da forma esférica do sítio Missão Nossa Senhora do Ó.

Foram encontrados apêndices do tipo asa e alça, como também um orifício em um fragmento de borda/bojo que foi reconstituído. Esse objeto possui forma e contorno simples, boca ampliada, e altura total maior que $1 / 2$ do diâmetro da boca e possui tratamento de superfície externa e interna polido. A presença desses elementos pode indicar uma necessidade de suspensão dos vasilhames, talvez para um melhor transporte dos mesmos. As vasilhas que possuem alças ou asas podem ter sido utilizadas para uso doméstico.

A queima predominante foi a completa com 1320 (82\%) fragmentos e a incompleta apenas com 296 (18\%) fragmentos, indicando uma queima bastante controlada.

\section{Perfil técnico 2}

O conjunto cerâmico que forma o perfil cerâmico 2 é composto por 51 fragmentos de cerâmica que possuem caracterizadores morfológicos e apenas 3 compõem a classe residual. A cerâmica histórica integrou uma classe distinta, sendo os elementos identificados nesse tipo de cerâmica a manufatura torneada e a vitrificação. Essa classe foi dividida ainda de acordo com Caldarelli (2003) em cerâmica vitrificada e leve (Gráfico 7). A cerâmica leve (41\%) (Figura 14) apresenta superfície com cor marrom clara e fragmentos pintados em vermelho. $A$ vitrificada (59\%) (Figura 15) apresenta coloração apenas em amarelo. 
Gráfico 7: Representação gráfica da divisão em classes da cerâmica histórica do Sítio Missão Nossa Senhora do Ó.
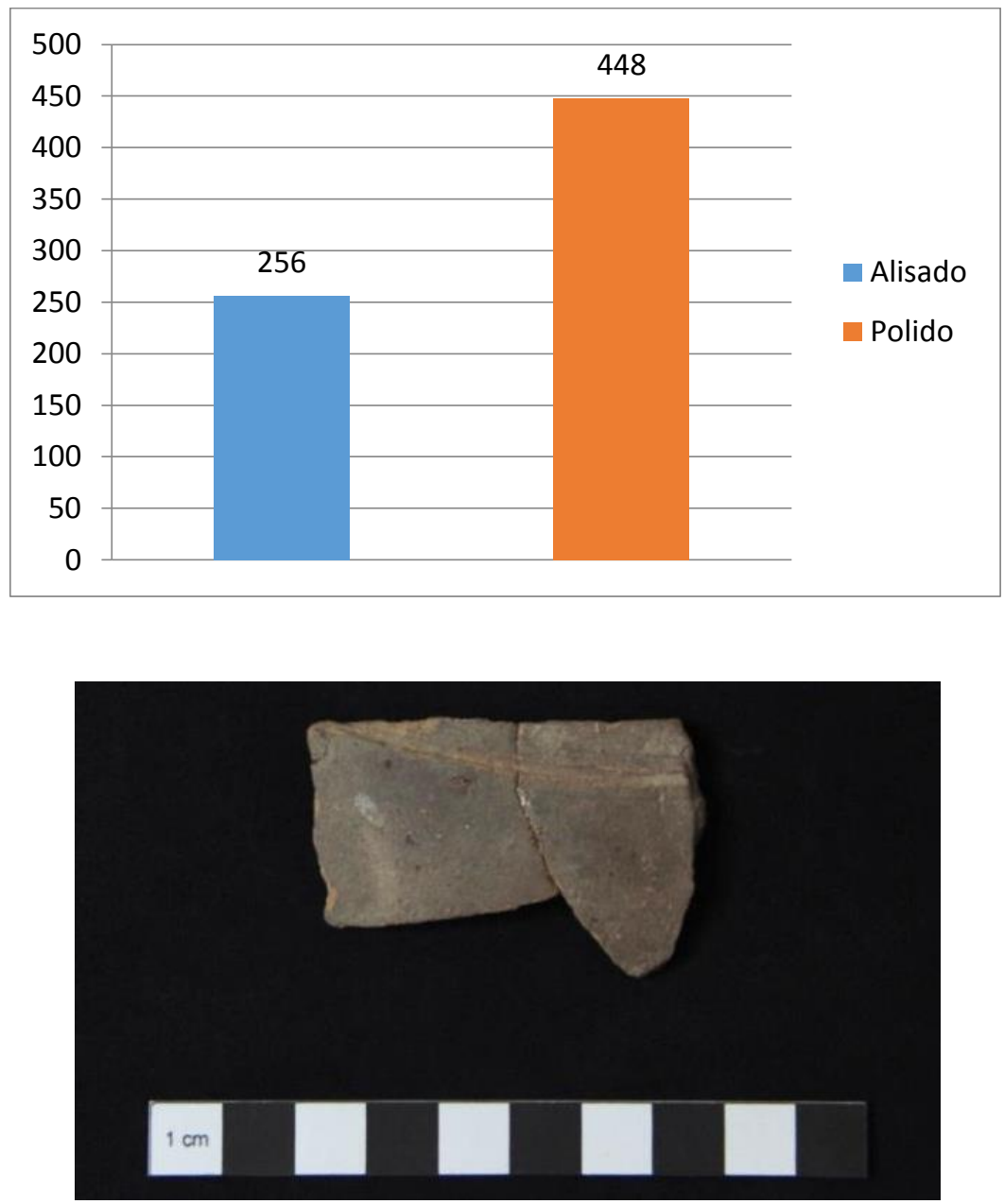

Figura 14: Fragmentos colados de cerâmica leve do Sítio Missão Nossa Senhora do Ó. Fonte: Lima, 2015.

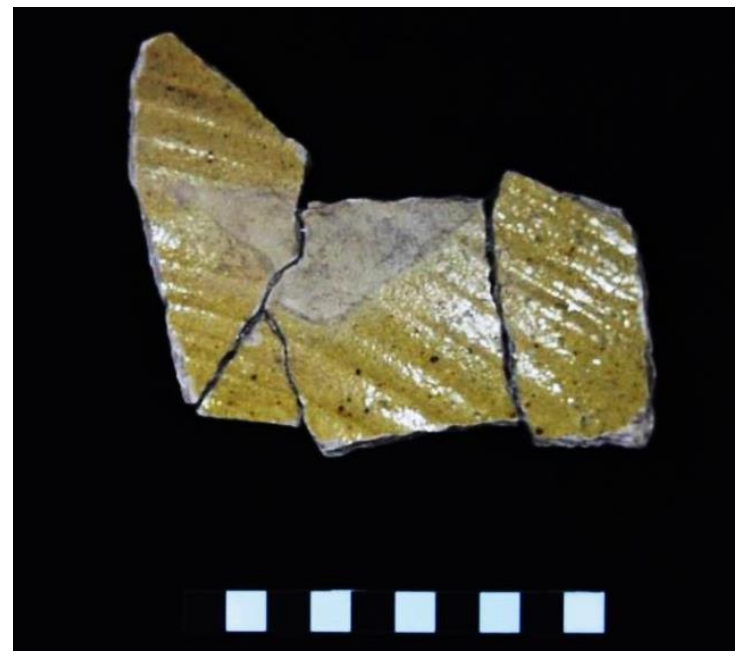

Figura 15: Fragmentos colados de cerâmica vitrificada do sítio Missão Nossa Senhora do Ó. Fonte: Lima, 2015. 
A pasta 5 foi encontrada nestes fragmentos, todos com areia fina; esta pasta possui uma homogeneidade apresenta grãos bem selecionados, sendo menores que $1 \mathrm{~mm}$, os fragmentos de cerâmica vitrificada possuem pasta com cor bege clara e os de cerâmica leve com cor marrom claro.

Houve uma predominância de fragmentos de bojo simples. Também foram identificadas bases planas, bordas e bordas/bojo e apenas um apêndice do tipo alça (Gráfico 8).

Gráfico 8: Representação gráfica do tipo de morfologia encontrados no material histórico do sítio Missão Nossa Senhora do Ó.

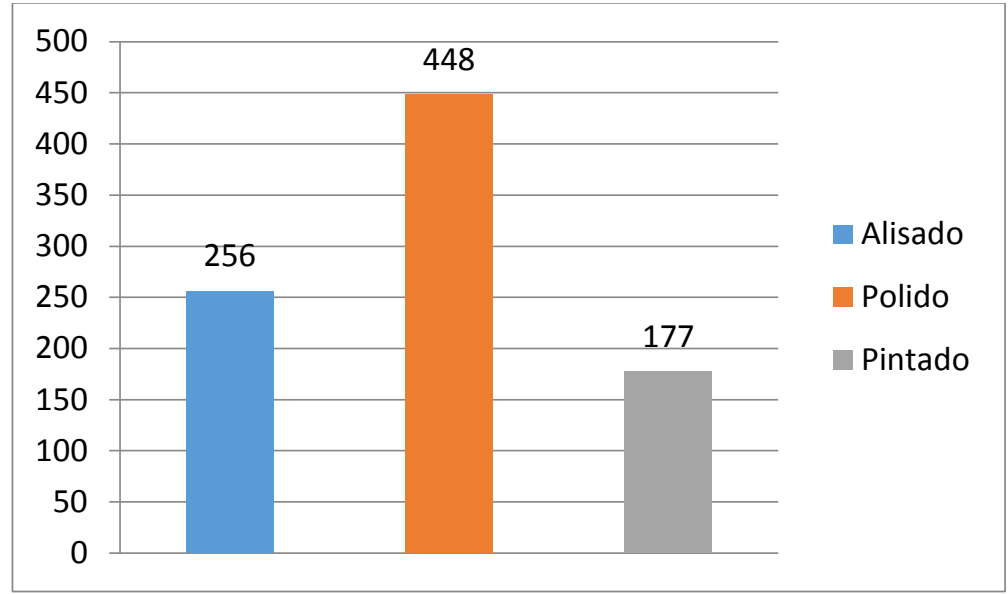

Foram identificados os tratamentos de superfície alisado, vitrificado e pintado, ambos foram realizados nas superfícies externas e internas dos fragmentos. Com uma predominância do tratamento de superfície externa alisada (78\%), seguido do pintado (18\%) e o vitrificado em poucos fragmentos (4\%). A técnica de manufatura verificada nos fragmentos que compõem este perfil foi a torneada e a queima completa.

\section{Análise Comparativa entre os Perfis Técnicos dos Sítios em Estudo}

Para a comparação entre os perfis técnicos e discussão sobre a continuidade e mudança tecnológica da produção cerâmica da llha de Sorobabel utilizou-se apenas os elementos verificados durante a análise laboratorial como: pasta, tratamento de superfície, queima, decoração, morfologia, espessura e forma. Não foram utilizados aspectos como a cronologia das ocupações ou a distribuição dos vestígios, pois não havia estas informações para os dois sítios.

Os fragmentos que possuem a pasta 03 são maioria nos dois sítios, como também a maior parte destes possuem tratamento de superfície externa e interna polidos com espessura de parede que varia de 0,4 a $1,5 \mathrm{~cm}$. Com a análise de Difração de Raios $X$, foi verificada a presença dos mesmos tipos de minerais, porém em quantidades distintas.

Os tipos de tratamentos de superfície são semelhantes tanto no sítio Ilha de Sorobabel quanto no sítio Missão Nossa senhora do Ó. Porém no sítio Missão Nossa senhora do Ó existe a associação entre diferentes técnicas de tratamento como o digitado, o digitado em associação 
com o escovado e o escovado com o pintado em vermelho. Nos objetos reconstituídos dos dois sítios houve a predominância do tratamento de superfície polido.

Verificou-se a presença de decorações plásticas nos sítios da llha de Sorobabel, com o escovado usado com maior frequência. Os fragmentos que possuem esse tipo de tratamento são, em maioria, das pastas 01 e a 02, com grãos de areia medindo cerca de $3 \mathrm{~mm}$ ou maiores. As decorações plásticas foram realizadas apenas na superfície externa dos vasilhames nos dois sítios, mas no sítio Missão Nossa Senhora do Ó houve uma maior variedade de motivos e uma maior quantidade de peças contendo tratamentos plásticos. Também foi constatada a presença de fragmentos com decoração pintada em vermelho nos dois sítios.

A pasta 04 foi utilizada em poucos fragmentos nos dois sítios, os fragmentos que possuem esse tipo de pasta estão associados ao tratamento polido e alisado, mas não é possível afirmar se foi algo intencional, pois também aparecem associados a outros tipos de tratamento plásticos e pintados, mas em menor quantidade.

A espessura dos fragmentos, tanto de borda, como de bojo se assemelham nos dois sítios, as bordas variam de 0,3 a $1 \mathrm{~cm}$ e os bojos de 0,4 a 1,8 cm, com exceção da cerâmica histórica do sítio Missão Nossa Senhora do Ó, que possui espessura de parede muito fina, o que não se assemelha em nenhum aspecto com a cerâmica do sítio llha de Sorobabel.

A queima predominante nos dois sítios foi a completa, e isso pode indicar que havia um controle sobre o processo de queima.

Nos dois sítios os objetos identificados foram apenas vasilhas. Quanto às formas reconstituídas verificou-se que todas do sítio Ilha de Sorobabel são abertas, como também, a maioria do sítio Missão Nossa Senhora do Ó. Quanto à caracterização das formas apenas a elipsoide horizontal de contorno simples, boca constrita, e altura total maior que $1 / 2$ do diâmetro da boca está presente nos dois sítios.

No sítio llha de Sorobabel as formas possuem as seguintes características: vasilhas com bordas diretas, bases arredondadas, as formas são elipsoide horizontal e ovoide. Apresentam boca ampliada com diâmetro variando de 22 à $27 \mathrm{~cm}$. Os tamanhos das vasilhas variam de 22 a 27 $\mathrm{cm}$. No sítio Missão Nossa Senhora do Ó, as formas possuem características de vasilhas com bordas diretas ou extrovertidas, todas possuem bojo simples e as formas são elipsoide horizontal, ovoide e esférica. Apresentam boca constrita ou aberta, com diâmetro variando de 8 a $28 \mathrm{~cm}$. Os tamanhos das vasilhas são médios e grandes. Possuem apêndices e apenas uma vasilha possui um orifício provavelmente utilizado para auxiliar na sustentação da vasilha, como mencionado anteriormente.

\section{Considerações Finais}

Através da análise dos elementos do perfil técnico cerâmico elaborado para cada sítio foi possível realizar algumas considerações sobre o material cerâmico da llha de Sorobabel. Foi verificado que houve uma continuidade tecnológica entre os sítios apenas em alguns elementos: na utilização da pintura em vermelho, na identificação de uma forma semelhante 
nos dois sítios (a elipsoide horizontal), a escolha de uma pasta com grãos selecionados (1 $\mathrm{mm}$ a $3 \mathrm{~mm}$ ) na maioria dos fragmentos com tratamento de superfície externa polido e pintado em vermelho.

Os indígenas da época do contato com os europeus foram aldeados em missões religiosas para sua catequização. Um dos fatores que podem comprovar uma mudança cultural é a presença de diferentes técnicas desenvolvidas no mesmo sítio, isso foi percebido no sítio Missão Nossa Senhora do Ó, podendo ter ocorrido devido a presença de várias etnias aldeadas na Missão de Nossa Senhora do Ó, onde os nativos podem ter assimilado as técnicas desenvolvidas uns pelos outros, como também em associação com as técnicas europeias, pois como citado anteriormente a técnica é aprendida e pode ser transmitida entre os membros de uma sociedade e isso é refletido e pode ser visto na cultura material deixada por esses grupos. Como mencionado na historiografia os índios Porcas/Procás e Pankararus habitavam a llha de Sorobabel no século XVIII e outras etnias podem ter passado ou habitado a área da missão anteriormente.

As técnicas de manufatura tradicionais dos nativos aldeados na missão, como o modelado e acordelado, continuaram a ser utilizadas, até determinado momento ou alguns artesãos passaram a utilizar a técnica torneada, mas não é possível precisar, pois não existem datações para estes sítios.

Os poucos fragmentos de cerâmica histórica de manufatura torneada do sítio Missão Nossa Senhora do Ó, não possuem nenhuma semelhança com os outros fragmentos encontrados no mesmo sítio e no llha de Sorobabel. Isto pode ser o resultado do aprendizado de novas técnicas a partir do contato ou o material cerâmico pode ser de um período mais recente. Novos estudos poderão responder essas e outras questões no sentido de aprofundar o nosso conhecimento sobre o passado destes grupos cuja cultura material chega transformada até os nossos dias.

\section{Referências}

CALDARELLI, S. B. Arqueologia do Vale do Paraíba Paulista SP-070 Rodovia Carvalho Pinto. 2003

CASTRO, V. M. C. Sítio Cana Brava: Contribuição ao Estudo dos Grupos Ceramistas Pré-históricos do Sudeste do Piauí. (Dissertação de Mestrado em História). Universidade Federal de Pernambuco, Recife. 1999

CHIARA, V. Viagem ao Redor do Pote. Clio Arqueológica, n. 13, p. 11-88. 1998

CHMYZ, I. Terminologia Arqueológica Brasileira para a Cêramica. Cadernos de Arqueológia, n. 1, Curitiba. 1976

ETCHEVARNE, C. Ambiente e Ocupação Humana em uma Região do Submédio São Francisco. Clio Arqueológica, n. 15, 1: 61-88. 2002

ERICSON, J.; STICKEL, E. A proposed classification system for ceramics. World Archaelogy, n. 4, p. 3: 357367. 1973

LEMONNIER, P. Elements for an Anthropology of Technology. Ann Arbor: Michigan. 1992 
LIMA, J. P. Continuidade e mudança tecnológica na cerâmica arqueológica da Ilha de Sorobabel, Itacuruba-PE. (Trabalho de Conclusão de Curso). Curso de Bacharelado em Arqueologia. Universidade Federal de Pernambuco, Recife. 2015

LUNA, S. Sobre as Origens da Agricultura e da Cerâmica Pré-histórica no Brasil. Clio Arqueológica, n. 16, 1:67-77. 2003

LUNA, S.; NASCIMENTO, A. As Pesquisas Arqueológicas Sobre Cerâmica no Nordeste do Brasil. Canindé Revista do Museu de Arqueologia de Xingó, n. 8, p. 167-207. 2006

MARTIN, G. Arqueologia nas Missões Religiosas do Nordeste do Brasil. Cadernos de Estudos Sociais, Recife, n. 1,v. 6. 1990

MARTIN, G. O Povoamento Pré-histórico do Vale do São Francisco. Clio Arqueológica, n. 13, 1: 9-41. 1998

MARTIN, G. Pré-história do Nordeste do Brasil. EDUFPE, Recife. 2013

MAUSS, M. Sociologia e Antropologia. Cosac Naify, São Paulo. 2003

MEDEIROS, R. P.; MUTZENBERG, D. Cartografia histórica das relocações indígenas nas ilhas do Submédio São Francisco no período pombalino. Revista Ultramares, v. 5, p. 01-19. 2014

NASCIMENTO, A.; LUNA, S. Procedimentos para a Análise da Cerâmica Arqueológica. Clio Arqueológica, n. 10, 1: 7-19. 1994

NOBRE, J. N. S. Memória Social e Espacialidade de Grupos Ceramistas em Trairi, CE. (Dissertação de Mestrado em Arqueologia). Universidade Federal de Pernambuco, Recife. 2013

OLIVEIRA, C. A. Estilos Tecnológicos da Cerâmica Pré-histórica no Sudeste do Piauí - Brasil. (Tese de Doutorado em Arqueologia). Universidade de São Paulo, São Paulo. 2000

PESSIS, A. M.. Registros Rupestres Perfil Gráfico e Grupo Social. Clio Arqueológica, n. 9, p. 8-14. 1993

RYE, O. S. Pottery Technology: Principals and Reconstruction. Taraxacum, Washington. 1981

SALVIA, F. L.; BROCHADO, J. P. Cerâmica Guarani. Posenato \& Cultura, Porto Alegre. 1989

SCATAMACCHIA, M. C. R. Proposta de terminologia para a descrição e classificação da cerâmica arqueológica dos grupos pertencentes à família lingüística Tupi-guarani. Revista do Museu de Arqueologia e Etnologia, 14: 291- 307. 2004

SCHIFER, M. B.; SKIBO, J. M. Theory and Experiment in the Study of Technological Change. Current Antropology, n. 5, 28:595-622. 1987

SILVA, J. C. Arqueologia no Médio São Francisco. Indígenas, Vaqueiros e Missionários. (Tese de Doutorado em História). Universidade Federal de Pernambuco, Recife. 2003

SHEPARD, A.. Ceramics for the archaeologist. Washington. 1963

TEJERO, N. C.; LITVAK, J. Un sistema de estudio para formas de vasijas. Depto de História/Instituto Nacional de Antropologia e História, México. 1968

ZUSE, S. Os Guarani e a Redução Jesuítica: Tradição e Mudança Técnica na Cadeia Operatória de Confecção dos Artefatos Cerâmicos do Sítio Pedra Grande e Entorno. (Dissertação de Mestrado em Arqueologia). Universidade de São Paulo, São Paulo. 2009

VIANA, S. A. Variabilidade Tecnológica do Sistema de Debitagem e Confeç̧ão dos Instrumentos Líticos Lascados de Sítios Lito-cerâmicos da Região do Rio Manso/MT. (Tese de Doutorado em História). Pontifícia Universidade Católica do Rio Grande do Sul, Porto Alegre. 2005 